\title{
PROBLEMS EXPERIENCED IN EVALUATING SUCCESS AND PERFORMANCE IN DISTANCE EDUCATION: A CASE STUDY
}

\author{
Dr. Ramazan YILMAZ \\ Faculty of Education, Bartin University \\ Bartin, Turkey
}

\section{ABSTRACT}

The need for distance education is increasing due to such reasons as keeping up with the changing social conditions, meeting the learning needs of the individuals and enabling them to be lifelong learners. In addition to many advantages distance education provides, it also has certain restrictions. One of these restrictions is the problems encountered in evaluating students' success and performance. The purpose of this study is to examine the viewpoints of lecturers regarding the evaluation process of academic success and performance of those students who are attending to online distance education program and to compare lecturers' views on assessment and evaluation practices carried out in face-to-face classroom environment with those online assessment and evaluation practices. The study was a case study and the data of the study were collected from the lecturers who lectured in a distant education program of a state university. Based on the findings of the study, the problems that lecturers have in evaluating the success and performance of the students in online distance education and possible solution suggestions for these problems are presented.

Key words: Distance education, assessment and evaluation, success, performance.

\section{INTRODUCTION}

It is seen that both in formal education and in distance education, the behavioralist understanding, practices and evaluation methods have been used until recently (Benson \& Brack, 2010). Such materials as the books, CDs, DVDs, videos or even educational software prepared by the teachers in distance education practices are materials prepared with a behavioralist approach. In the preparation process of these materials, teachers prepare the learning content and the materials based on the behaviors that students will be equipped with and deliver these materials and content to the students. Students are expected to study the content in the given materials and be successful.

However, as a result of the reflection of constructivist approach on distance education practices recently, there is a movement from pure transformation of information in education towards social construction of information (Benson \& Brack, 2010; Lucas, Gunawardena, \& Moreira, 2014; Tenenbaum, Naidu, Jegede, \& Austin, 2001; Wen, Tsai, \& Chuang, 2004; Zhang et al., 2015). Developments in ICT and their reflections on education also contributed to the progress of this process. Accordingly, the use of such interactions tools and environments as forum, blogs, social networks, web conferences in distance education improved the interaction between teacher, student and content (Hernandez, Montaner, Sese, \& Urquizu, 2011; Thoms \& Eryilmaz, 2014; Uzunboylu, Bicen, \& Cavus, 2011) and decreased the perception of transactional distance among these elements (Ekwunife-Orakwue \& Teng, 2014). By discussing on the subject in these medium and through these tools, teachers and students contribute to the development of the learning content and thus, ensure that the information is constructed socially (Benson \& Brack, 2010; Mbati, 2013; Thormann, Gable, Fidalgo, \& Blakeslee, 2013). The most 
important responsibility in implementing constructivist approach in online distance education programs is on the teachers who deliver online distance education courses.

Although there are significant changes and developments in ICT and although the reflections of these changes and developments are seen on education, one of the most important problems in online distance education practices is the issue of evaluating student success and performance. When the literature is reviewed, it is seen that mostly the assessment and evaluation practices used in traditional face-to-face classroom environments are used for evaluating student success and performance in online distance education programs. For example, in Turkish Higher Education System, the success and performance evaluation process in distance education programs is subject to a regulation.

According to this regulation; "Distance education programs and assessment and evaluation activities relating to the courses provided through distance education could be carried out face-to-face or in electronic medium, either attended or unattended, using the assessment and evaluation methods (assignments, project studies, written exams or oral exams etc.) approved by the senates of higher education institutions in line with the curriculum or in the form of a central examination. Mid-term exams could be carried out unattended in electronic medium if required; whilst final exams and make-up exams shall be carried out attended either in face-to-face or electronic medium. Where and how these exams will be carried out as well as which assessment and evaluation methods such as oral exams, performance exams, project, thesis and portfolios, will be used is determined by the senate upon the request of the relevant department. The rate of unattended assessment and evaluation activities on overall success cannot be more than $20 \%$ in distance education" (YOK, 2013).

It is seen that there is not a standardization of the assessment and evaluation activities of higher education institutions of today. Each university individually determines which evaluation methods they will use as well as according to which parameters they will score or the type of assessment and evaluation practices. Therefore, a lot of problems are encountered. According to the aforementioned regulation, whilst the rate of mid-term exams on overall evaluation cannot be more than $20 \%$, the rate of final exams cannot be less than $\mathbf{8 0 \%}$. And this is in fact, something that is against the philosophy behind distance education. Ensuring the reliability dimensions of examinations could be determining factors in the fact that final examinations have higher effect on overall evaluation compared to mid-term exams and that final exams are carried out in traditional classroom environment (Benson \& Brack, 2010; Williams, Howell, \& Hricko, 2006; Mardanian \& Mozelius, 2011). However, online practices based on constructivist approach using traditional assessment and evaluation methods in measuring students' success and performance could be a contradiction. What is wondered here is what kind of a path should be followed in evaluating success and performance in distance education.

When the literature is reviewed, it is seen that in addition to traditional examinations various alternative practices are used in evaluating student performance and success in online distance education. In online examinations, which is one of those practices, students are asked to log into the examination in online medium and to answer the questions given in this medium at a given period of time. In online examinations, mostly multiple choice, true-false, fill-in-the-blank and open-ended questions are used (Costa, Mullan, Kothe, \& Butow, 2010; Gikandi, Morrow, \& Davis, 2011; Jordan, 2011; Marriott, 2009; Terzis \& Economides, 2011; Wang, 2007, 2008, 2010). According to the literature, both traditional and online examination practices are mostly used to assess resultoriented success rather than student performance in the process and whether this assessments measure students' success truly is open to discussion. Recently, it is seen that such alternative assessment and evaluation practices as e-portfolio, concept maps, projects, collaborative studies, assignments, self-assessment, peer assessment, online discussions, learning analytics have started to be used in online distance education as 
alternatives to exam practices (Chang, Tseng, Chou, \& Chen, 2011; Gikandi, Morrow, \& Davis, 2011; Gress, Fior, Hadwin, \& Winne, 2010; Wang, 2008, 2011; Yang \& Tsai, 2010). Such interaction tools and media as e-mails, blogs, forums, e-portfolio systems used in online distance education enable teachers to make alternative assessment and evaluation and makes it easier (Gray et al., 2012; Kear, Donelan, \& Williams, 2012; Kecik et al., 2012; Terzis, Moridis, \& Economides, 2012). In addition, the reflections of constructivist philosophy in education support alternative assessment and evaluation. However, the most important factor in implementing all these is the teachers lecturing in online distance education programs. Teachers' technology and pedagogy knowledge, their knowledge and experience on alternative assessment and evaluation techniques, their attitudes and beliefs towards these techniques are factors effecting the acceptance and use of alternative assessment and evaluation techniques.

It is important to see the advantages and restrictions of this approach that aforementioned university use in evaluating success and performance in distance education. Thus, according to the results of this model, it will be possible to develop a model with better quality in evaluating success and performance in distance education. When the literature is reviewed, no study looking into the practices, in which online and traditional assessment and evaluation techniques are used together in evaluating student performance and success in distance education, and relevant lecturers' opinions. Therefore, it is believed that this study will fill an important gap in the literature. So, this case study compares online and traditional assessment and evaluation practices from the viewpoint of lecturers who are attending to online distance education program with the problems encountered in assessing student success and performance; and based on the opinions of the lecturers suggestions for solutions were made. In line with this overall objective, answers to the following research questions were looked into:

$>$ Which assessment and evaluation methods and practices do lecturers use in assessing students' success and performance online?

$>$ To what extent do lecturers follow and chose to use the latest developments on assessment and evaluation methods?

$>$ What are lecturers' opinions on using alternative assessment and evaluation techniques in online assessment and evaluation processes?

$>$ What are the difficulties lecturers face in assessing student performance and success in distance education and what are their solution suggestions?

\section{METHOD}

This section includes information on the research model, study group, data collection tool and analysis of data in the study.

\section{Research Model}

The study is designed according to case study which is a qualitative research design. The main feature of qualitative case study is in-depth investigation of one or more cases (Yin, 2013). Both qualitative and quantitative research methods are used together in the study. Whilst the quantitative data was collected using a questionnaire developed by the researcher, the qualitative data was collected through semi-structured interview forms which was also developed by the researcher.

\section{Study Group}

The study was conducted on 46 lecturers who work at online distance education programs of a state university. The demographic information on the lecturers is given in Table 1 below. 
Table 1. Demographic information of the lecturers

\begin{tabular}{llll}
\hline Variable & Group & N & $\%$ \\
\hline \multirow{2}{*}{ Gender } & Female & 12 & 27 \\
& Male & 34 & 73 \\
\hline Total & & 46 & 100 \\
\hline \multirow{2}{*}{$\begin{array}{l}\text { Professional } \\
\text { Experience }\end{array}$} & 6-5 Years & 17 & 37 \\
& $11-15$ Years & 11 & 24 \\
& $16-20$ Years & 14 & 30.4 \\
\hline Total & 21 Years and more & 2 & 4.3 \\
\hline \multirow{2}{*}{ Total Number } & & 2 & 4.3 \\
Courses They Deliver in & 1 Course & 46 & 100 \\
Distance Education & 2 Courses & 19 & 41.4 \\
& 3 Courses & 11 & 24 \\
& 4 Courses & 6 & 13 \\
Total & 5 Courses and more & 5 & 10.8 \\
\hline
\end{tabular}

Whilst mid-term exams in the distance education programs in which the study was conducted were carried out through online assessment and evaluation practices, final exams were conducted in the form of traditional examinations carried out in traditional face-to-face classroom environments. Following the exams, lecturers, who worked in online distance education programs for one year, were asked to complete the data collection forms developed by the researcher.

Learning management system through which online distance education practices would be conducted and alternative assessment and evaluation tools integrated into this system were introduced to the lecturers, who would deliver courses in online distance education programs, before the beginning of the academic year and they were informed about how these can be used in assessment and evaluation processes. There are synchronous discussion (web conference), asynchronous discussion (forum), forming questionnaire, creating e-portfolio, assignment preparation instruments, blogs, social network tools, online examination practices (true-false, multiple choice, classical, short answer etc.) on Moodle which is the online learning management system through which lecturers deliver their course. Lecturers were introduced on how to use these tools in assessing student success and performance before the beginning of the academic year. In addition, lecturers were informed about creating digital concept maps and puzzles, collaborative project studies, assignment practices, self-assessment, peer-assessment and online discussion techniques.

\section{Data Collection Tools}

The data in the study were collected through a questionnaire and a semi-structured interview form developed by the researcher. The questionnaire comprises of two parts. The first part includes questions on demographic information of the participants. The second part includes questions on the assessment and evaluation techniques that lecturers use in distance education as well as questions on whether they follow and chose to use the latest developments on assessment and evaluation.

In semi-structured interview forms, lecturers were asked questions towards determining the reasons they prefer alternative assessment and evaluation methods in distance education, the restrictions before using alternative assessment and evaluation methods in distance education, the problems encountered in evaluating student success and performance in distance education and solutions towards solving these problems. 


\section{Data Analysis}

Content analysis method was used in analyzing the qualitative data. The data emerged from the research was examined in detail by the researchers and, themes and codes were identified. The data were coded by two researchers with the coding reliability percentage found at $86 \%$. For the remaining $14 \%$, the researchers came together to discuss and reconciled.

\section{FINDINGS}

Descriptive statistics showing which assessment and evaluation methods and practices do lecturers use in assessing students' success and performance online are given in Table 2 below.

Table 2. Assessment and evaluation techniques that lecturers prefer to use

\begin{tabular}{|c|c|c|c|c|c|c|c|c|c|c|}
\hline \multirow{2}{*}{$\begin{array}{l}\text { Assessment and evaluation techniques lecturers } \\
\text { use in online learning }\end{array}$} & \multicolumn{2}{|c|}{ Always } & \multicolumn{2}{|c|}{ Generally } & \multicolumn{2}{|c|}{ Sometimes } & \multicolumn{2}{|c|}{ Rarely } & \multicolumn{2}{|c|}{ Never } \\
\hline & $\mathbf{f}$ & $\%$ & $\mathbf{f}$ & $\%$ & $\mathbf{f}$ & $\%$ & $\mathbf{f}$ & $\%$ & $\mathbf{f}$ & $\%$ \\
\hline Online oral examinations & 1 & 2.2 & 6 & 13.0 & 7 & 15.2 & 4 & 8.7 & 28 & 60.9 \\
\hline Online written (open-ended) examinations & 13 & 28.3 & 16 & 34.8 & 8 & 17.4 & 3 & 6.5 & 6 & 13.0 \\
\hline Online multiple choice examinations & 12 & 26.1 & 18 & 39.1 & 8 & 17.4 & - & - & 8 & 17.4 \\
\hline Online true-false examinations & 7 & 15.2 & 11 & 23.9 & 9 & 19.6 & 5 & 10.9 & 14 & 30.4 \\
\hline Online short-answer examinations & 5 & 10.9 & 16 & 34.8 & 7 & 15.2 & 3 & 6.5 & 15 & 32.6 \\
\hline E-portfolio & 4 & 8.7 & 7 & 15.2 & 7 & 15.2 & 8 & 17.4 & 20 & 43.5 \\
\hline Digital concept maps & 2 & 4.3 & 5 & 10.9 & 4 & 8.7 & 4 & 8.7 & 31 & 67.4 \\
\hline Assignments & 5 & 10.9 & 14 & 30.4 & 7 & 15.2 & 4 & 8.7 & 16 & 34.8 \\
\hline Check list & - & - & 2 & 4.3 & 10 & 21.7 & 3 & 6.5 & 31 & 67.4 \\
\hline Rubric & 2 & 4.3 & 2 & 4.3 & 7 & 15.2 & 3 & 6.5 & 32 & 69.6 \\
\hline $\begin{array}{l}\text { Making students prepare and present e- } \\
\text { presentation }\end{array}$ & 4 & 8.7 & 9 & 19.6 & 8 & 17.4 & 1 & 2.2 & 24 & 52.2 \\
\hline Self-assessment & 3 & 6.5 & 5 & 10.9 & 8 & 17.4 & 2 & 4.3 & 28 & 60.9 \\
\hline Peer-assessment & 2 & 4.3 & 3 & 6.5 & 5 & 10.9 & 2 & 4.3 & 34 & 73.9 \\
\hline Group assessment & 1 & 2.2 & 2 & 4.3 & 10 & 21.7 & 2 & 4.3 & 31 & 67.4 \\
\hline
\end{tabular}

The assessment and evaluation techniques lecturer prefer to use in mid-term exams are given in Table 2. When "Always" and "Generally" options in the questionnaire are examined, it is seen that lecturers mostly prefer "online multiple choice exams" $(f=30)$ and "online written (classical) exams $(f=29)$ for online assessment and evaluation. These two options were followed by "online short-answer exams" $(f=21)$ and "assignments" $(f=19)$ and "online true-false exams" $(f=18)$. When above given assessment and evaluation choices are examined, it is seen that all of them except assignments are the electronic versions of traditional exams. In other words, it is seen that lecturers do not prefer alternative assessment and evaluation techniques in assessing success and performance.

In line with the second research question in the study, descriptive statistics showing to what extent lecturers follow and chose to use the latest developments on assessment and evaluation methods are given in Table 3. 
Table 3. Descriptive statistics on to what extent lecturers follow and chose to use the latest developments on assessment and evaluation methods

\begin{tabular}{lll}
\hline Following the latest techniques on assessment and evaluation & $\mathbf{f}$ & $\%$ \\
\hline I do not follow & 12 & 26 \\
I partially follow & 14 & 30.4 \\
I follow & 20 & 43.6 \\
\hline Total & 46 & 100 \\
\hline Choosing evaluation techniques which take students to the center & $\mathbf{f}$ & $\%$ \\
during the evaluation process & 4 & 8.7 \\
\hline I do not prefer & 12 & 26.1 \\
I rarely prefer & 23 & 50.0 \\
I sometimes prefer & 7 & 15.2 \\
I always prefer & 46 & 100 \\
\hline Total & & \\
\hline
\end{tabular}

When Table 3 was analyzed, it was seen that 12 lecturers giving courses in distance education stated that they did not follow the developments on the latest techniques on assessment and evaluation whilst 14 of them indicated that they partially follow these developments and 20 of them indicated that they followed these developments. In addition, when their choice of evaluation techniques which take students to the center during the evaluation process was examined, 4 of the lecturers indicated that they did not prefer these techniques, whilst 12 of them indicated that they rarely preferred, 23 of them indicated that they sometimes preferred and 7 of them indicated that they always preferred these techniques. When the results from Table 2 and Table $\mathbf{3}$ are examined in general, although almost half of the lecturers indicated that they followed the developments in assessment and evaluation, it is seen that they rarely prefer student-centered alternative assessment and evaluation practices in success and performance evaluation. The data collected through semi-structured interview forms in order to find out the reason of this case was analyzed using content analysis. In line with the third research question, lecturers were asked why they chose such alternative assessment and evaluation techniques as e-portfolio, digital concept maps, self-assessment, peer assessment in distance education. The views of the lecturers are given in Table 4.

Table 4. The Reasons behind lecturers' choice of alternative assessment and evaluation techniques in distance education

\begin{tabular}{ll}
\hline Sub-themes & f \\
\hline Because it makes students active and eager in the learning process & 32 \\
Because it gives clues about whether learning has been achieved or about the quality & 26 \\
of learning & 22 \\
Because it contributes to the development of the student & 18 \\
Because it gives students the opportunity to show their competencies and performance & 18 \\
Because it enables assessing students' knowledge and skills throughout the process of & 15 \\
education & \\
Because it gives students the opportunity to communicate with each other and to & 12 \\
cooperate & 8 \\
Because it gives the opportunity to assess student development from different views & 8 \\
Because it gives the opportunity to follow student development systematically & 8 \\
Because it improves students scientific research skills & 4 \\
Because it makes it easier to know about the students & 2 \\
Because it gets students adopt the habit of studying & 1 \\
Because it enables students to access more resources in the process of learning & 1 \\
Because it enables peer assessment & 1 \\
Because it encourages students to prepare for the course & 1 \\
\hline Because it ensures consistency in assessment and evaluation &
\end{tabular}

When the content analysis findings given in Table 4 are examined, it is seen that the reason behind lecturers' choice of alternative assessment and evaluation techniques are seen as "Because it makes students active and eager in the learning process" ( $f=32)$, "Because it gives clues about whether learning has been achieved or about the quality of learning" ( $f=26)$ and "Because it contributes to the development of the student" $(f=22)$. Table 5, on the other hand, includes the content analysis of the data collected from semi- 
structured interviews in order to determine the restrictions caused by using alternative assessment and evaluation techniques in online distance education.

Table 5. Restrictions of utility of

alternative evaluation techniques in distance education

\begin{tabular}{ll}
\hline Sub-themes & f \\
\hline $\begin{array}{l}\text { Because using alternative assessment and evaluation techniques alone is } \\
\text { considered insufficient }\end{array}$ & 12 \\
$\begin{array}{l}\text { Because the evaluation takes a long time, and requires a lot of time and effort } \\
\text { Because it is difficult to determine whether the assignment was made by the }\end{array}$ & $\mathbf{1 0}$ \\
$\begin{array}{l}\text { student or not } \\
\text { Because it does not provide same opportunities that face-to-face communication }\end{array}$ & $\mathbf{8}$ \\
$\begin{array}{l}\text { and interaction with students does } \\
\text { Because it can not prevent cheating }\end{array}$ & 3 \\
$\begin{array}{l}\text { Because it might not be convenient for cases in which instant feedback is } \\
\text { necessary }\end{array}$ & 2 \\
$\begin{array}{l}\text { Because it is not possible to determine to what extent students understand the } \\
\text { subject }\end{array}$ & 2 \\
$\begin{array}{l}\text { Because the information found on internet sources is put into assignments by } \\
\text { copying and pasting it without checking whether it is correct or not and } \\
\text { presented to the lecturer }\end{array}$ & 2 \\
\hline
\end{tabular}

When the content analysis findings in Table 5 is analyzed, it is seen that what lecturers see as restrictions of alternative assessment and evaluation techniques are "Because using alternative assessment and evaluation techniques alone is considered insufficient" $(f=12)$ "Because the evaluation takes a long time, and requires a lot of time and effort" $(f=10)$ and "Because it is difficult to determine whether the assignment was made by the student or not" $(f=8)$. In line with the fourth research question of the study, the results of the content analysis collected from the semi-structured interview forms conducted to determine the problems that lecturers delivering courses in online distance education face in evaluating students' success and performance are shown in Table 6.

Table 6. The problems lecturers face in evaluating student performance and success in distance education

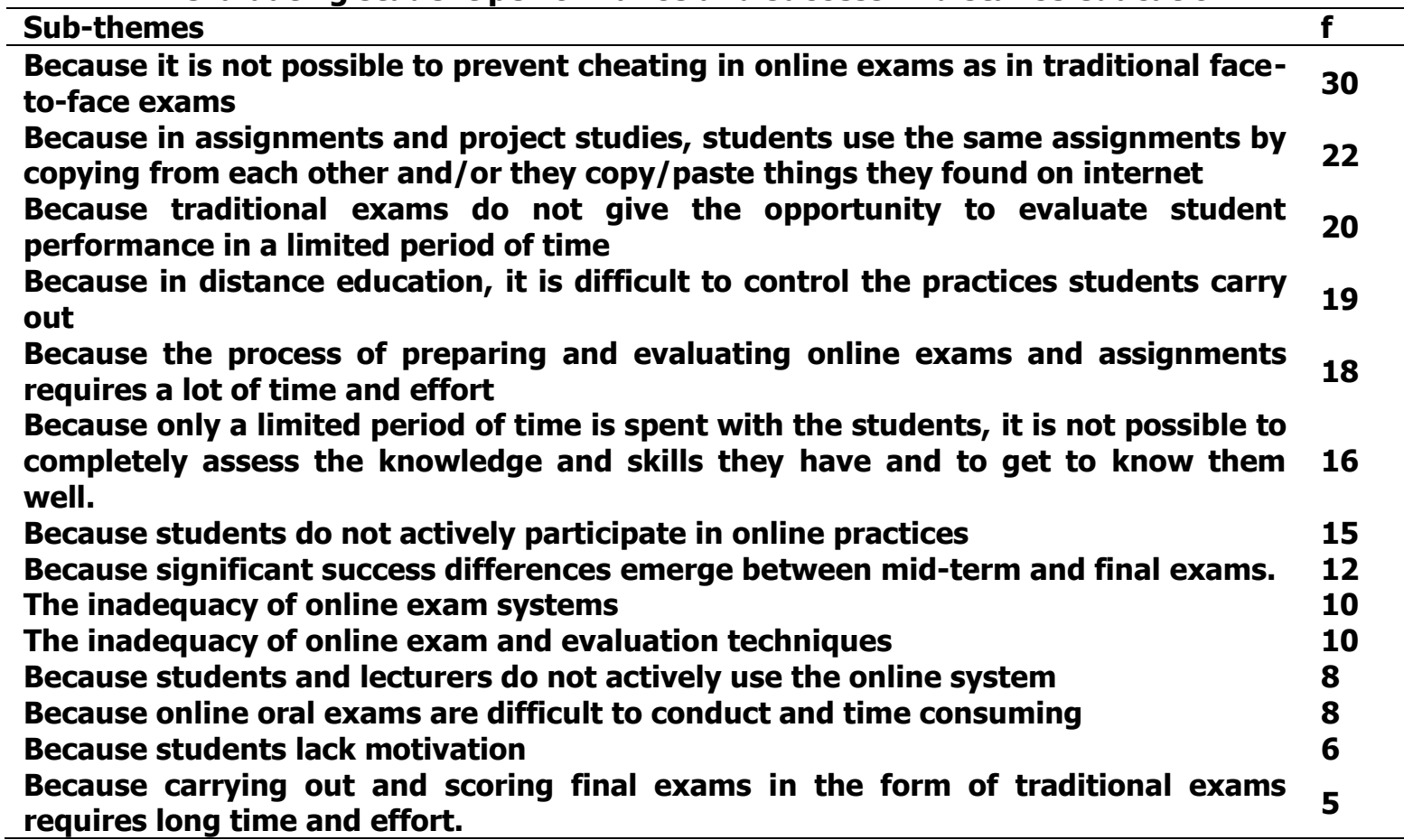


The results of content analysis given in Table 6 shows the problems encountered in implementing mid-term exams and final exams. Accordingly, it is seen that one of the most frequently experienced problems of the lecturers is "not being able to prevent cheating during the exams" $(\mathrm{f}=30)$. And this problem is followed by "in assignments and project studies, students use the same assignments by copying from each other and/or they copy/paste things they found on internet" $(\mathrm{f}=22)$. And because traditional exams are conducted in a limited period of time $(f=20)$ lecturers consider that inadequate to evaluate student success and performance. Besides, the fact that it is difficult to control the assignments and projects students carry out in distance education $(f=19)$ is considered as an important deficiency. Also, lecturers state that the process of preparing and evaluating online exams and assignments requires a lot of time and effort $(\mathrm{f}=18)$.

The opinions of the lecturers that they stated as possible solutions to the aforementioned problems relating to evaluating student success and performance in distance education were analyzed via content analysis and the results are given in Table 7 below.

Table 7. Suggestions of lecturers relating to the problems experienced in evaluating student success and performance in distance education

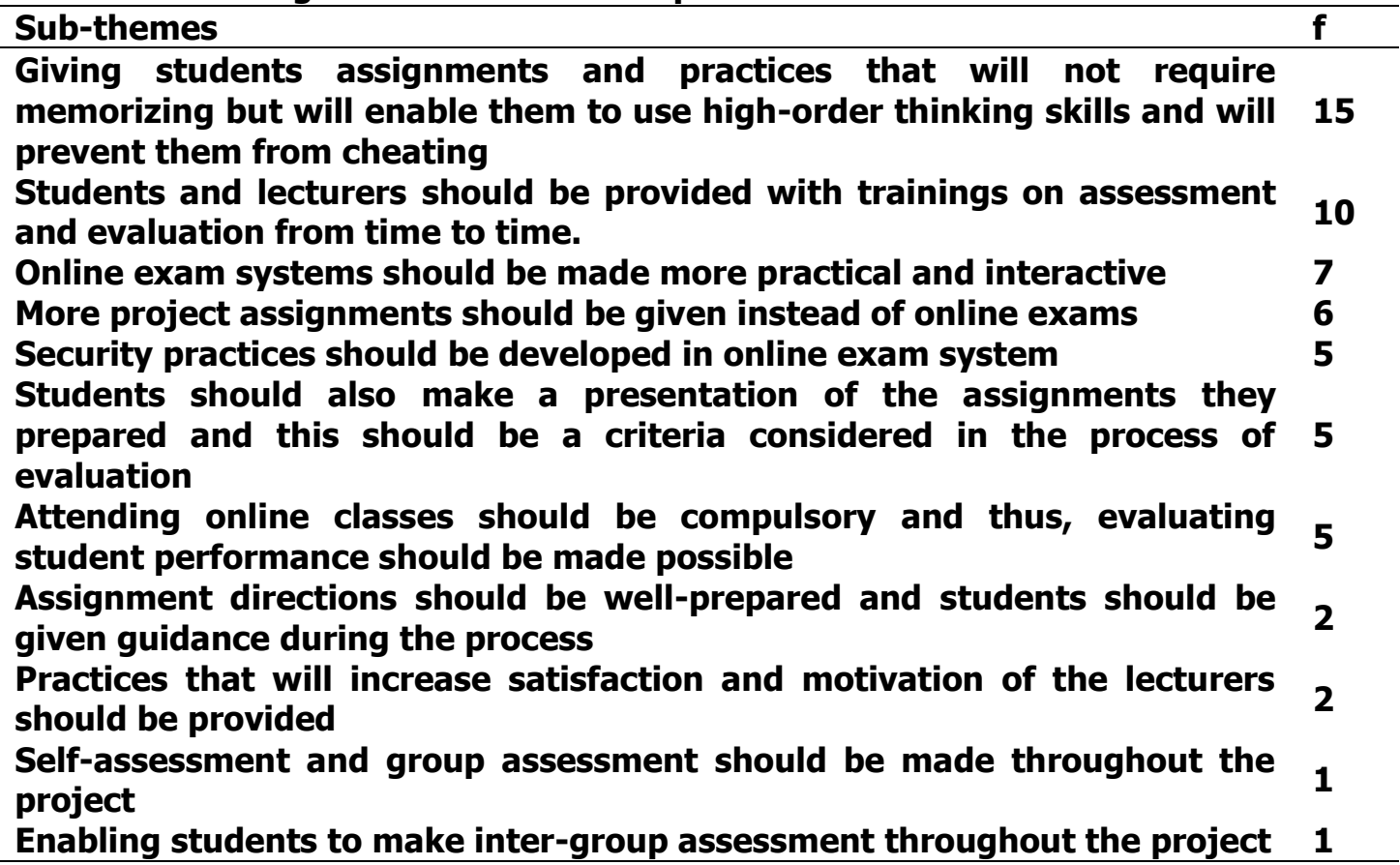

When the result of content analysis given in Table 7 is examined, it is seen that the most often indicated solution relating to evaluating student success and performance in distance education is giving students assignments and practices that will not require memorizing but will enable them to use high-order thinking skills and will prevent them from cheating $(f=15)$. Another solution offered is providing students and lecturers with trainings on online assessment and evaluation practices $(f=10)$. In addition, increasing interaction possibilities in online exam practices $(f=7)$ is another solution offered. Also, increasing the encouragement and motivation of lecturers on developing online assessment and evaluation practices and using alternative evaluation techniques are outstanding solution suggestions.

\section{DISCUSSION, CONCLUSION AND SUGGESTIONS}

When the difficulties faced in evaluating student success and performance in distance education were examined, it was seen that the main problem faced in online exams, compared to traditional exams, was the cheating problem. Lecturers indicated that they faced similar problems also in assignment and project studies and that students copied 
and pasted things they found on internet or copied one another's assignment in assignment and project studies. The studies in the literature support this finding (Harmon \& Lambrinos, 2008; King, Guyette, \& Piotrowski, 2009; Olt, 2002; Watson \& Sottile, 2010). Mardanian and Mozelius (2011) indicate that they experience similar problems in online environment and that it is difficult to prevent this. Lecturers expressed that it was not possible to control students in online environment and this prevented them from getting to know and observing students in all aspects. From another point of view, lecturers indicated that it was not possible to evaluate success and performance in a limited period of time during final exams. These findings indicate that lecturers do not find online exams reliable and that they find traditional exams inadequate in evaluating success and performance.

When online assessment and evaluation choices of the lecturers are examined, it is seen that most often used techniques were online exams (open-ended questions, multiple choice questions, true-false questions, short-answer questions etc.). It is seen that online exams are followed by assignments. When lecturers' opinions and evaluations on alternative assessment and evaluation techniques are examined, it is seen that most of the lecturers indicate that they follow the latest developments in assessment and evaluation and that they prefer to use student-centered evaluation techniques. In addition, lecturers express that alternative assessment and evaluation techniques will make students active and eager during the learning process, will make it easier to follow the learning process of the student, will make it easier to for students to show their performance and will improve cooperation and communication among students. Considered from this point of view, it is seen that lecturers are aware of the possible benefits of alternative assessment and evaluation practices. And when the reason behind not using these alternative assessment and evaluation practices despite having the awareness is examined, it is seen that lecturers indicate that preparing and evaluating these alternative assessment and evaluation practices take a lot of time and effort. Also, it is understood that lecturers need to have knowledge and experience on how they can use alternative assessment and evaluation techniques in distance education. Because of all aforementioned, it is seen that lecturers prefer online exam practices. Similar findings were obtained in a study carried out by Tomei (2006) and it is indicated that while the workload that traditional evaluation bring on lecturers is stable, online evaluation has a fluctuated nature.

When the possible solution suggestions of the lecturers regarding the problems in evaluating success and performance in distance education is examined, it is seen that the most often suggested solution is including alternative assessment and evaluation practices in mid-term exams and that these practices should not include memorizing information but rather, enable students to use high-order thinking skills and prevent them from cheating. Also, it is seen that lecturers state that both lecturers and students should be provided with trainings on online assessment and evaluation practices. Another solution suggested is that the instructions of online assessment and evaluation practices should be well-prepared and should be easy-to-understand for students and should guide them.

Taking all these realities into account, utilizing alternative assessment and evaluation practices to solve aforementioned problems in the process of evaluating success and performance in distance education will be more convenient, and these practices will enable social construction of knowledge by creating social constructivist learning environments and also will improve communication interaction in distance education (Gaytan \& McEwen, 2007; McLoughlin \& Luca, 2001; Robles \& Braathen, 2002; Vonderwell, Liang, \& Alderman, 2007). Preparing seminars for lecturers and students on how to use alternative assessment and evaluation practices in evaluation process and introducing the weaknesses and strengths of each alternative techniques; and providing them with guidebooks and materials will be useful. The support of the management is of great importance in encouraging lecturers to use alternative assessment and evaluation techniques. Distance education managers should support lecturers on this issue and 
provide incentives for them. Using the same teaching and evaluation activities used in traditional environments will cause to quality and satisfaction problems in distance education (Benson \& Brack, 2010; Dunn, Morgan, O'Reilly, \& Parry, 2003). Therefore, it is believed that providing lecturers who deliver/will deliver distance education courses with regular technological and pedagogical trainings regarding teaching and evaluation dimensions will be useful.

In future studies, the acceptance and utilization of alternative assessment and evaluation techniques shown to lecturers during such events as seminars can be examined within the scope of technology acceptance model and the acceptance and utilization of each technique can be evaluated and thus, a model suggestion can be made within the framework of accepted evaluation techniques. In addition, the impact of using formative and summative evaluation techniques together in the process of evaluating success and performance could be looked into. Here formative assessment could be provided to students online and they could be made to assess themselves and see what they could not learn.

It is thought that in formative evaluation process, there will not be any problems if students show cheating behaviors. Because student will look for resources in this process and interact with his/her peers. And at this point, formative evaluation will serve its objective and contribute to the learning process of the student. However, the impact of formative evaluation in overall evaluation should be smaller. In summative evaluation, on the other hand, such activities as e-portfolio preparing, project studies can be included. Taking acceptance and belief status of lecturers into consideration, summative evaluation process can be supported with traditional assessment and evaluation activities. The efficiency of such an evaluation model blended this way can be examined.

\section{BIODATA and CONTACT ADDRESSES of AUTHOR}

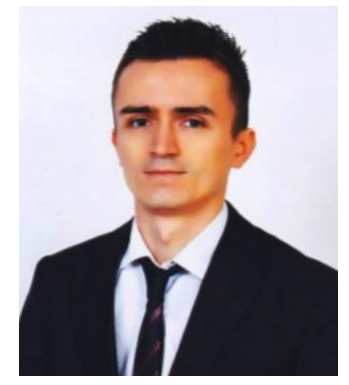

Dr. Ramazan YILMAZ is an assistant professor in the Department of Computer Education \& Instructional Technology at Bartin University in Turkey. He received his B.S. degree from Hacettepe University, Faculty of Education, Department of CEIT in 2007. In 2010, he received his M.A. degree in CEIT from Gazi University. In 2014, he received his Ph.D. degree in CEIT from Ankara University. He is interested in instructional design, online learning, community of practice, multimedia learning, socio-psychological variables and pedagogical agents.

\section{Dr. Ramazan YILMAZ}

Department of Computer Education and Instructional Technology, Faculty of Education, Bartin University

74100, Bartin, Turkey

Phone: +903782235253

E-mail: ramazanyilmaz067@gmail.com

\section{REFERENCES}

Benson, R., \& Brack, C. (2010). Online learning and assessment in higher education: A planning guide. Elsevier.

Chang, C. C., Tseng, K. H., Chou, P. N., \& Chen, Y. H. (2011). Reliability and validity of Web-based portfolio peer assessment: A case study for a senior high school's students taking computer course. Computers \& Education, 57(1), 1306-1316.

Costa, D. S., Mullan, B. A., Kothe, E. J., \& Butow, P. (2010). A web-based formative assessment tool for Masters students: A pilot study. Computers \& Education, 54(4), 1248-1253. 
Dunn, L., Morgan, C., O'Reilly, M., \& Parry, S. (2003). The student assessment handbook: New directions in traditional and online assessment. Routledge. EkwunifeOrakwue, K. C., \& Teng, T. L. (2014). The impact of transactional distance dialogic interactions on student learning outcomes in online and blended environments. Computers \& Education, 78, 414-427.

Gaytan, J., \& McEwen, B. C. (2007). Effective online instructional and assessment strategies. The American Journal of Distance Education, 21(3), 117-132.

Gikandi, J. W., Morrow, D., \& Davis, N. E. (2011). Online formative assessment in higher education: A review of the literature. Computers \& Education, 57(4), 2333-2351.

Gray, K., Waycott, J., Clerehan, R., Hamilton, M., Richardson, J., Sheard, J., \& Thompson, C. (2012). 'Worth it? Findings from a study of how academics assess students' Web 2.0 activities'. Research in Learning Technology, 20(1).

Gress, C. L., Fior, M., Hadwin, A. F., \& Winne, P. H. (2010). Measurement and assessment in computer-supported collaborative learning. Computers in Human Behavior, 26(5), 806-814.

Harmon, O. R., \& Lambrinos, J. (2008). Are online exams an invitation to cheat?. The Journal of Economic Education, 39(2), 116-125.

Hernandez, B., Montaner, T., Sese, F. J., \& Urquizu, P. (2011). The role of social motivations in e-learning: How do they affect usage and success of ICT interactive tools?. Computers in Human Behavior, 27(6), 2224-2232.

Jordan, S. (2011). Using interactive computer-based assessment to support beginning distance learners of science. Open Learning, 26(2), 147-164.

Kear, K., Donelan, H., \& Williams, J. (2014). Using wikis for online group projects: Student and tutor perspectives. The International Review of Research in Open and Distributed Learning, 15(4).

Kecik, I., Aydin, B., Sakar, N., Dikdere, M., Aydin, S., Yuksel, I., \& Caner, M. (2012). Determining the feasibility of an e-portfolio application in a distance education teaching practice course. The International Review of Research in Open and Distributed Learning, 13(2), 160-180.

King, C. G., Guyette Jr, R. W., \& Piotrowski, C. (2009). Online exams and cheating: An empirical analysis of business students' views. Journal of Educators Online, $6(1)$.

Lucas, M., Gunawardena, C., \& Moreira, A. (2014). Assessing social construction of knowledge online: A critique of the interaction analysis model. Computers in Human Behavior, 30, 574-582.

Mardanian, H., \& Mozelius, P. (2011). A Reliable, Efficient, Affordable and User-friendly Approach for Online Assessment in Distance Education. In Never Waste a Crisis!: Inclusive Excellence, Innovative Technologies and Transformed Schools as Autonomous Learning Organisations (pp. 18-25).

Marriott, P. (2009). Students' evaluation of the use of online summative assessment on an undergraduate financial accounting module. British Journal of Educational Technology, 40, 237-254. 
Mbati, L. (2013). Online social media applications for constructivism and observational learning. The International Review of Research in Open and Distributed Learning, 14(5).

McLoughlin, C., \& Luca, J. (2001). Quality in online delivery: What does it mean for assessment in e-learning environments. In A Proceedings of the Annual Conference of the Australasian Society for Computers in Learning in Tertiary Education (ASCILITE) (Vol. 18).

Olt, M. R. (2002). Ethics and distance education: Strategies for minimizing academic dishonesty in online assessment. Online journal of distance learning administration, 5(3).

Robles, M., \& Braathen, S. (2002). Online assessment techniques. Delta Pi Epsilon Journal, 44(1), 39-49.

Terzis, V., \& Economides, A. A. (2011). The acceptance and use of computer based assessment. Computers \& Education, 56(4), 1032-1044.

Terzis, V., Moridis, C. N., \& Economides, A. A. (2012). The effect of emotional feedback on behavioral intention to use computer based assessment. Computers \& Education, 59(2), 710-721.

Tenenbaum, G., Naidu, S., Jegede, O., \& Austin, J. (2001). Constructivist pedagogy in conventional on-campus and distance learning practice: An exploratory investigation. Learning and instruction, 11(2), 87-111.

Thormann, J., Gable, S., Fidalgo, P. S., \& Blakeslee, G. (2013). Interaction, critical thinking, and social network analysis (SNA) in online courses. The International Review of Research in Open and Distributed Learning, 14(3), 294-318.

Uzunboylu, H., Bicen, H., \& Cavus, N. (2011). The efficient virtual learning environment: A case study of web $\mathbf{2 . 0}$ tools and Windows live spaces. Computers \& Education, 56(3), 720-726.

Vonderwell, S., Liang, X., \& Alderman, K. (2007). Asynchronous discussions and assessment in online learning. Journal of Research on Technology in Education, 39(3), 309-328.

Wang, T. H. (2007). What strategies are effective for formative assessment in an eLearning environment? Journal of Computer Assisted Learning, 23(3), 171-186.

Wang, T. H. (2008). Web-based quiz-game-like formative assessment: Development and evaluation. Computers \& Education, 51(3), 1247-1263.

Wang, T. H. (2010). Web-based dynamic assessment: Taking assessment as teaching and learning strategy for improving students' e-Learning effectiveness. Computers $\&$ Education, 54(4), 1157-1166.

Wang, T. H. (2011). Developing Web-based assessment strategies for facilitating junior high school students to perform self-regulated learning in an e-Learning environment. Computers \& Education, 57(2), 1801-1812.

Watson, G. R., \& Sottile, J. (2010). Cheating in the digital age: Do students cheat more in online courses?. Online Journal of Distance Learning Administration 13(1). 
Wen, M. L., Tsai, C. C., Lin, H. M., \& Chuang, S. C. (2004). Cognitive-metacognitive and content-technical aspects of constructivist Internet-based learning environments: a LISREL analysis. Computers \& Education, 43(3), 237-248.

Williams, D.D., Howell, S.L. \& Hricko, M. (2006). Online assessment, measurement, and evaluation: emerging practices. Information Science Publishing.

Yang, Y. F., \& Tsai, C. C. (2010). Conceptions of and approaches to learning through online peer assessment. Learning and Instruction, 20(1), 72-83.

Yin, R. K. (2013). Case study research: Design and methods. Sage publications.

YOK. (2013). Rules and Procedures Related to Distance Education in Higher Education Institutions. Retrieved from http://www.yok.gov.tr/documents/ 10279/34559/uzaktan_ogretim_esas_usul.pdf/b8177cd6-5b3c-407a-9978f8965419b117

Zhang, X., Gao, Y., Yan, X., de Pablos, P. O., Sun, Y., \& Cao, X. (2015). From e-learning to social-learning: Mapping development of studies on social media-supported knowledge management. Computers in Human Behavior, 51(B), 803-811. 